\title{
Responsabilidade fiscal de grandes municípios brasileiros: uma análise de suas características
}

\author{
Claudia Ferreira da Cruz \\ Universidade Federal do Rio de Janeiro \\ Marcelo Álvaro da Silva Macedo \\ Universidade Federal do Rio de Janeiro \\ Fernanda Filgueiras Sauerbronn \\ Universidade Federal do Rio de Janeiro
}

\begin{abstract}
Este estudo teve por objetivo identificar quais características podem contribuir para explicar o nível de responsabilidade fiscal de grandes municípios brasileiros. Foi realizado um estudo com dados em painel, no período de 2002 a 2009, e os resultados indicaram que os municípios pesquisados apresentam um nível incipiente de responsabilidade fiscal. As variáveis nível econômico e autonomia financeira apresentaram relação positiva significativa com o nível de responsabilidade fiscal, e a variável endividamento, relação negativa. O modelo de regressão estimado revelou que região, localização e ano também podem influenciar a responsabilidade fiscal dos municípios. Espera-se que este estudo contribua para a discussão sobre as variações no nível de responsabilidade fiscal dos municípios por meio da sugestão de métrica de avaliação, além dos dispositivos que constam nos instrumentos normativos.
\end{abstract}

Palavras-chave: responsabilidade fiscal; grande município; métricas de avaliação.

Responsabilidad fiscal de grandes municipios brasileños: un análisis de sus características Este estudio tuvo como objetivo identificar cuales características pueden contribuir para explicar el nivel de responsabilidad fiscal de grandes municipios brasileños. Fue realizado un estudio con datos de panel, en el período de 2002 a 2009, y los resultados indicaron que los municipios encuestados presentan un nivel incipiente de responsabilidad fiscal. Las variables nivel económico y autonomía financiera presentaron una relación positiva significativa con el nivel de responsabilidad fiscal, y la variable endeudamiento, una relación negativa. El modelo de regresión estimado reveló que región, localización y año también pueden influenciar la responsabilidad fiscal de los municipios. Se espera con el estudio contribuir para la discusión acerca de las variaciones en el nivel de responsabilidad fiscal de los municipios por medio de la sugerencia de métrica de evaluación, además de los dispositivos que constan en los instrumentos normativos.

Palabras clave: responsabilidad fiscal; grande municipio; métricas de evaluación.

Artigo recebido em 17 dez. 2012 e aceito em 26 ago. 2013. 


\section{Fiscal responsibility of large Brazilian cities: an analysis of its characteristics}

This study aimed to identify which characteristics may contribute to explain the fiscal responsibility level of large Brazilian cities. It was conducted with panel data, within the period from 2002 to 2009, and the results indicated that the cities under analysis present an incipient fiscal responsibility level. The variables economic level and financial autonomy presented a significant positive relation to the fiscal responsibility level, and the variable debt, a negative relation. The estimated regression model revealed that region, location, and year can also influence the fiscal responsibility of cities. It is expected that this study contributes to the discussion on variations in the fiscal responsibility level of cities by suggesting evaluation metric, in addition to the devices listed in the normative instruments.

KEYWORDs: fiscal responsibility; large city; evaluation metrics.

\section{Introdução}

O presente artigo tem como foco identificar as características associadas ao nível de responsabilidade fiscal de grandes municípios brasileiros. Segundo Heald (2003), a transparência da gestão fiscal constitui uma forma de aperfeiçoar os mecanismos de governança, promover a estabilidade fiscal, melhorar o funcionamento do setor público e promover a melhoria do ambiente econômico para o setor privado.

A gestão fiscal refere-se à relação existente entre receitas e despesas públicas. No Brasil, durante um longo período essa relação apresentou-se desequilibrada para muitos órgãos e entes da administração pública brasileira. As reformas por que passou o Brasil a partir da década de 1990, depois da abertura política, trouxeram em seu bojo uma discussão quanto ao equilíbrio das contas públicas, que culminou com a aprovação da Lei Complementar no 101/2000, a chamada Lei de Responsabilidade Fiscal (LRF).

A LRF dispõe sobre normas aplicáveis às três esferas governamentais e determina uma série de restrições aos gestores públicos com vistas a alcançar equilíbrio e controle na gestão dos recursos públicos. Embora a discussão em torno da responsabilidade na gestão fiscal dos recursos públicos já seja tema recorrente em pesquisas, ganhou maior destaque no Brasil com a aprovação da LRF.

No Brasil, os municípios constituem a esfera governamental de menor abrangência, sendo os mais numerosos, e, a partir da Constituição de 1988, receberam atribuições que aumentaram suas necessidades de recursos financeiros e técnicos para planejar e executar os serviços públicos sob sua responsabilidade (Abrúcio, 2010).

O orçamento público ainda é o principal instrumento em que os gestores expressam suas preferências na alocação dos recursos para provimento de bens públicos. A partir das determinações da Constituição de 1988, o planejamento orçamentário no Brasil conta com instrumentos de curto e médio prazo, que são a Lei de Diretrizes Orçamentárias (LDO), a Lei Orçamentária Anual (LOA) e o Plano Plurianual (PPA). De maneira geral, tais instrumentos visam priorizar o planejamento de receitas e despesas, a partir das metas de atuação de cada ente, de modo a assegurar a responsabilidade e o equilíbrio fiscal nos ciclos orçamentários. O 
fechamento do ciclo orçamentário se dá com a avaliação e a prestação de contas aos respectivos órgãos de controle externo em cada esfera (Nascimento, 2010).

Durante alguns anos, as contas de muitos municípios brasileiros se apresentavam em situação de descontrole e desequilíbrio, o que implica pouca eficiência e responsabilidade na aplicação dos recursos e também é indicativo de um planejamento pouco eficaz.

Nos dispositivos legais e na literatura correlata, o conceito de responsabilidade fiscal encontra-se associado às ideias de planejamento, controle, transparência e eficiência na utilização de recursos, porém uma das grandes questões ainda sem consenso está na forma como a responsabilidade fiscal de uma entidade deve ser mensurada. A maior parte das iniciativas de avaliação da responsabilidade e eficiência fiscal no setor público tem-se restringido a parâmetros relacionados ao cumprimento de metas definidas em leis e outros instrumentos normativos (Nascimento, 2010).

Portanto, conhecer os fatores relacionados a essas entidades que podem explicar diferentes níveis de responsabilidade fiscal pode contribuir para encontrar critérios de avaliação adequados. Este estudo se justifica pela potencialidade de identificar variáveis relacionadas ao desempenho fiscal dos municípios e objetiva responder a seguinte pergunta: quais características podem contribuir para explicar o nível de responsabilidade fiscal de grandes municípios brasileiros?

Para responder à pergunta da pesquisa, o presente estudo colocou foco em municípios brasileiros de grande porte, utilizando-se o recorte temporal de 2002 a 2009. As variáveis consideradas no estudo são: nível de responsabilidade fiscal, tamanho, nível econômico, autonomia financeira, nível de endividamento, ciclo político, região e localização dos municípios. Os autores partem da premissa de que municípios com maior tamanho, maior nível econômico, maior autonomia financeira, menor endividamento e localizados em regiões mais desenvolvidas tendem a apresentar melhor desempenho fiscal. Além disso, admite-se que o ciclo político, decorrente do exercício de primeiro ou segundo mandato, após reeleição, pode exercer influência em sua responsabilidade fiscal (Ferraz e Finan, 2011), haja vista que estudos no Brasil e no exterior têm encontrado evidências de que esses têm incentivos diferenciados em mandatos diferentes.

O artigo está estruturado em cinco seções, sendo a primeira delas esta introdução. Na segunda seção é discutido o referencial teórico que dá sustentação ao estudo, pondo ênfase sobre a responsabilidade na gestão fiscal e as possíveis dimensões de análise. Na terceira seção é apresentada a metodologia empregada na pesquisa, dando-se ênfase ao detalhamento operacional e constitutivo das variáveis. Na quarta seção são apresentados os resultados do estudo e, por fim, na última seção são traçadas considerações quanto às principais características que explicam uma gestão fiscal responsável e suas implicações para a administração pública brasileira.

\section{Referencial teórico}

Em 4 de maio de 2000 foi aprovada a Lei complementar nํ 101, conhecida como Lei de Responsabilidade Fiscal (LRF). Esse instrumento normativo estabelece normas de finanças 
públicas voltadas para a responsabilidade na gestão fiscal aplicáveis à União, aos estados, ao Distrito Federal e aos municípios.

De acordo com o disposto na LRF, artigo 1으, $\S 1^{\circ}$ :

A responsabilidade na gestão fiscal pressupõe a ação planejada e transparente, em que se previnem riscos e corrigem desvios capazes de afetar o equilíbrio das contas públicas, mediante o cumprimento de metas de resultados entre receitas e despesas e a obediência a limites e condições no que tange a renúncia de receita, geração de despesas com pessoal, da seguridade social e outras, dívidas consolidada e mobiliária, operações de crédito, inclusive por antecipação de receita, concessão de garantia e inscrição em Restos a Pagar.

Portanto, a lei complementar dispõe que, para que uma entidade tenha responsabilidade na gestão fiscal, é necessário fundamentar-se em quatro pilares: planejamento, transparência, controle e responsabilidade. Conforme disposto na própria lei, esses pilares contribuem para uma gestão fiscal responsável, em conformidade com os princípios constitucionais, por estarem relacionados à destinação adequada dos recursos públicos, de acordo com as finalidades para as quais foram arrecadados e com as determinações legais.

No que tange ao pilar do planejamento, a Constituição de 1988 já dispusera sobre a integração entre os processos de planejamento e orçamento ao prever a elaboração dos três instrumentos básicos para esse fim: o plano plurianual (PPA), as diretrizes orçamentárias e os orçamentos anuais (art. 165, I, II e III).

O pilar da transparência está disposto na LRF como decorrente do incentivo à participação da sociedade e da realização de audiências públicas no processo de elaboração e no curso da execução dos planos. A LRF determina ainda ampla divulgação, inclusive em meios eletrônicos de acesso público, de todos os atos e fatos ligados à arrecadação de receitas e à realização de despesas pelas entidades públicas.

Em relação ao pilar do controle, a LRF estabeleceu um mecanismo na forma de conselho de gestão fiscal: "o acompanhamento e a avaliação, de forma permanente, da política e da operacionalidade da gestão fiscal serão realizados por conselho de gestão fiscal, constituído por representantes de todos os Poderes e esferas de Governo, do Ministério Público e de entidades técnicas representativas da sociedade" (art. 67). Conforme previsto na Constituição Federal, o controle externo pode ser exercido pelas atribuições do Poder Legislativo, que conta com o auxílio dos Tribunais de Contas.

E, finalmente, o pilar da responsabilidade se dá pela exigência do gestor público por meio da imposição de sanções ao descumprimento das regras estabelecidas na LRF. Isso culminou com a aprovação da Lei $n^{0}$ 10.028/2000, conhecida como Lei de crimes de responsabilidade fiscal.

A LRF também esclarece os requisitos essenciais da responsabilidade na gestão fiscal, quais sejam, a instituição, a previsão e a efetiva arrecadação de todos os tributos da competência constitucional do ente da Federação. 
Apesar dos conceitos, dos pilares e dos requisitos para a consecução de uma gestão fiscal eficiente e responsável, muitos pesquisadores que estudam questões relacionadas à responsabilidade e à eficiência na gestão fiscal de recursos públicos se deparam com um problema comum: identificar uma proxy adequada para avaliar o quanto uma determinada entidade é responsável e eficiente do ponto de vista fiscal.

Diversos estudos avaliam a questão de responsabilidade fiscal por meio de parâmetros que relacionam cumprimento de prazos, limites de endividamento e de gastos em determinadas áreas, a partir de dispositivos legais que determinam tais parâmetros. Porém, existem autores que questionam se as restrições impostas em leis e outros normativos são adequados para caracterizar um comportamento responsável e eficiente do ponto de vista fiscal.

No Brasil, uma das iniciativas para avaliar o nível de responsabilidade fiscal dos municípios foi tomada pela Confederação Nacional dos Municípios (CMN), por meio da criação do Índice de Responsabilidade Fiscal, Social e de Gestão (IRFS). Segundo a CNM, o IRFS é um instrumento que objetiva disseminar a cultura da responsabilidade fiscal associada à responsabilidade social. O índice reflete anualmente o desempenho dos municípios sob três óticas, oferecendo um parâmetro simples e, ao mesmo tempo, amplo de avaliação das administrações municipais. O IRFS é formado por três subíndices (fiscal, social e gestão), os quais são compostos por outros índices específicos, totalizando 16. Esses índices são calculados a partir de informações enviadas pelos municípios à Secretaria do Tesouro Nacional (STN) e a outros órgãos oficiais. O subíndice fiscal do IRFS é utilizado no presente trabalho por permitir analisar a gestão fiscal sob ótica do cumprimento dos limites previstos em lei. Decerto, a medida utilizada não contempla todas as óticas sob as quais a gestão fiscal pode ser avaliada ou mensurada.

Além disso, pesquisas acadêmicas têm empreendido esforços no sentido de contribuir para a avaliação da responsabilidade e da eficiência fiscal das entidades públicas, bem como compreender que variáveis podem influenciar o desempenho fiscal de tais entidades. A seguir são apresentados alguns desses estudos que têm foco na avaliação e nas características da gestão fiscal eficiente e responsável em entidades públicas.

Gobetti e Klering (2007) desenvolveram um estudo no qual propuseram uma metodologia de avaliação da trajetória fiscal dos estados e municípios e análises consistentes sobre qualidade de gestão e nível de enquadramento dos entes subnacionais aos limites e parâmetros da LRF. Os autores denominaram a metodologia de Índice de Responsabilidade Fiscal e de Qualidade de Gestão (IRF-QG), o qual é construído a partir de uma média de indicadores relacionados aos balanços orçamentários e patrimoniais dos municípios. O trabalho diferencia-se por incluir informações adicionais, além das análises das despesas de pessoal e do endividamento dos governos. Os dados utilizados pelos autores revelaram que os municípios com os melhores índices fiscais apresentam médias inferiores aos demais no índice de qualidade de gestão. A análise dos dados apontou ainda para a existência de uma margem considerável de "contabilidade criativa" nos balanços de estados e municípios, o que implica a necessidade de aprimorar a transparência orçamentária e consolidar a uniformização de procedimentos contábeis nas três esferas de governo. 
Giuberti (2005) pesquisou o efeito da LRF sobre os municípios brasileiros, por meio da avaliação da situação fiscal dos municípios, se essa situação necessitava ser controlada através da imposição de uma regra e se o limite imposto sobre as despesas com pessoal afeta esses municípios e contribui para redução do gasto público. Os resultados apontaram que a despesa com pessoal apresentada pelo conjunto dos municípios brasileiros nos últimos anos ficou abaixo do limite estabelecido pela lei. Conclui-se que há espaço para uma elevação desse gasto, sem que isso indique uma infração à mesma, o que implica que a LRF afeta de modo positivo o gasto com pessoal.

Costa (2006) analisou a influência de variáveis fiscais nas eleições municipais brasileiras de 2004, a partir do modelo proposto por Mendes (2004), que utiliza um modelo probit com seleção. O autor concluiu que se reelegem com mais frequência os prefeitos que conseguem maior expansão das despesas correntes municipais e que obtêm maior volume de transferências correntes e de capital. Os resultados revelaram que, para prefeitos que buscam a reeleição, a expansão da despesa e da receita de transferências correntes tem sido estratégia vitoriosa e que induz ao crescimento do governo ao longo do tempo.

Nakaguma e Bender (2006) estudaram o comportamento fiscal dos estados brasileiros no período 1986-2002, analisando, em particular, o impacto de mudanças institucionais sobre os ciclos políticos orçamentários e sobre o desempenho fiscal dos estados. Os resultados obtidos apontam que a Emenda da Reeleição implicou a intensificação dos ciclos políticos e que a LRF constituiu um instrumento efetivo para o controle do endividamento e para a redução das despesas de custeio dos estados.

Romero (2006) testou se o voto individual é sensível ao que os incumbentes realmente fazem, o que se expressa por meio de suas preferências alocativas, com a utilização de dados no período de 1960-76. Esse autor encontrou evidências fortes de que a possibilidade de continuar o mandato ou transmiti-lo a outros do mesmo grupo exerce influência da alocação de recursos pelos incumbentes, dado que os eleitores têm acesso a essas informações.

Barreto e Mendonça (2010) avaliaram o efeito da descentralização fiscal e do processo de ajuste de suas contas públicas sobre os indicadores de pobreza e de bem-estar dos estados brasileiros, no período de 2000 a 2009, e os resultados relevaram um efeito positivo na melhoria dos indicadores sociais nas unidades federativas.

Nascimento e Vicente (2012) pesquisaram de que forma os indicadores contábeis podem estar relacionados ao comportamento "oportunista" dos governantes, entendido como aquele que é direcionado à sua permanência no poder ou à de seus aliados políticos. Os resultados apontaram efeitos significativos no Resultado Orçamentário e Resultado Orçamentário Corrente, geração de caixa, elevação do resultado financeiro apurado no balanço patrimonial e aumento das despesas de investimentos na probabilidade de recondução. Com isso, os autores concluíram que a assimetria informacional exerce uma influência significativa nos ciclos políticos.

Não obstante as contribuições trazidas pelos estudos citados, a responsabilidade na gestão fiscal é per se um tema que encerra relevância social, por envolver recursos públicos, os quais têm impacto econômico em qualquer que seja a abrangência das entidades consideradas. Isso faz com que existam muitas oportunidades de pesquisa que possam expandir a fronteira 
do conhecimento na área, entre elas uma investigação quanto às características que explicam o nível de responsabilidade fiscal, especificamente, de grandes municípios brasileiros.

\section{Metodologia}

Para responder à pergunta de pesquisa do presente estudo, torna-se necessário nessa seção apresentar a amostra selecionada e as principais fontes secundárias de dados relacionados à gestão fiscal responsável. Torna-se também fundamental apresentar as variáveis do estudo em termos operacionais e constitutivos (Vieira e Zouain, 2003).

\subsection{Amostra}

De acordo com dados do Instituto Brasileiro de Geografia e Estatística (IBGE, 2010), o Brasil possui uma população de aproximadamente 190,75 milhões de habitantes, os quais estão distribuídos em 5.564 municípios. Nesse estudo optou-se por investigar os municípios considerados de grande porte, tanto os que são capitais dos estados, quanto os que se localizam no interior, os quais constituem a população-alvo. Dessa forma, o critério adotado foi o recorte dos 100 maiores municípios brasileiros de acordo com a população, porém foram excluídos: Brasília (por não apresentar as características político-administrativas comuns aos municípios brasileiros), Campos dos Goytacazes, São João de Meriti, Petrópolis e Várzea Grande, pela indisponibilidade de dados necessários ao estudo, totalizando 95 municípios na amostra final. Esses municípios concentram 73 milhões de habitantes, 38,5\% do total da população do país. Isso torna o estudo relevante por investigar informações relativas às características que contribuem para explicar a responsabilidade fiscal de uma parcela bastante significativa da população brasileira e que em 2009 respondeu por mais de 50\% de toda a riqueza produzida no país. Entre os 95 mais populosos municípios brasileiros estão contempladas todas as regiões, porém nem todos os estados, uma vez que o estado do Tocantins não possui nenhum município entre os mais populosos considerados na amostra.

O espaço temporal contemplado nesta pesquisa foram os exercícios de 2002 a 2009 , perfazendo um total de oito anos. Esse período foi considerado em decorrência da disponibilidade de dados para levantamento de indicadores de responsabilidade fiscal dos municípios, que têm como marco inicial a aprovação da Lei Complementar no 101/2000.

Trata-se de uma amostragem não probabilística e os resultados encontrados devem ser considerados para a amostra e períodos considerados. A amostra final ficou composta por 760 municípios-ano, o que forma um painel balanceado.

\subsection{Dados}

Os dados necessários ao desenvolvimento desse estudo foram obtidos nas seguintes fontes: Confederação Nacional dos Municípios (CNM, 2002-2010); Instituto Brasileiro de 
Geografia e Estatística (IBGE, 2010); Secretaria do Tesouro Nacional (STN, 2002-2010) - Base de dados Finanças do Brasil (Finbra); Tribunal Superior Eleitoral (TSE) — Resultados das Eleições.

\subsection{Premissas e variáveis de estudo}

Esse estudo admite a premissa de que municípios com maior tamanho, maior nível econômico, maior autonomia financeira, menor endividamento e localizados em regiões mais desenvolvidas tendem a apresentar melhor desempenho fiscal. Além disso, admite-se que o ciclo político (fato de o prefeito municipal estar em primeiro ou segundo mandato) pode exercer influência em sua responsabilidade fiscal, haja vista que estudos no Brasil e no exterior têm encontrado evidências de que esses têm incentivos diferenciados em mandatos diferentes: Ferejohn (1986), Barro (1973), Brender e Drazen (2005), Ferraz e Finan (2011), Mendes e Rocha (2003), Meneguin e Bugarin (2001), Meneguin, Bugarin e Carvalho (2005) e Porto e Porto (2000).

Assim, as variáveis selecionadas para o estudo foram:

i. Índice de Responsabilidade Fiscal (IRF): representado pelo subíndice fiscal do Índice de Responsabilidade Fiscal, Social e de Gestão (IRFS) calculado pela Confederação Nacional de Municípios (CNM) ${ }^{1}$ desde 2002, considerando os seguintes componentes: endividamento, suficiência de caixa, gasto com pessoal e superávit primário. Essa variável foi disponibilizada para o período de 2002 a 2010, porém o ano de 2010 não foi considerado no estudo em decorrência da indisponibilidade de outras variáveis. Os dados relativos ao IRFS foram obtidos junto à CMN por meio de solicitação formal após contato telefônico. Neste estudo, essa variável é considerada variável dependente, por representar o nível de responsabilidade fiscal dos municípios, que constitui o objeto de investigação.

ii. Tamanho do Município: receita orçamentária, representada pelo montante total (expresso em milhões de reais) arrecadado pelo município no exercício, considerando receitas correntes e de capital. Constitui uma variável que expressa o tamanho do município em termos de arrecadação de recursos para custeio dos serviços públicos. Embora tenham sido considerados grandes municípios brasileiros, os valores de arrecadação apresentam magnitudes diferentes, pelo que se optou por considerar o logaritmo natural da receita orçamentária dos municípios em cada ano. Os dados relativos à receita orçamentária foram coletados na homepage da Secretaria do Tesouro Nacional (STN), que disponibiliza a base de dados Finanças do Brasil (Finbra), com séries anuais para municípios a partir do ano de 1989. Pinho (2006) assume o pressuposto de que os municípios com melhores condições econômicas, so-

\footnotetext{
${ }^{1}$ O subíndice fiscal é calculado pela média dos valores padronizados das variáveis endividamento, suficiência de caixa, gasto com pessoal e superávit primário — todas tendo como denominador a receita corrente líquida —, sendo a padronização feita pela atribuição do valor 0,500 ao valor médio de cada variável.
} 
ciais, políticas e tecnológicas tendem a maior nível de accountability. Dessa forma, propõe-se a hipótese de que o tamanho é uma característica que tem influência significativa no nível de responsabilidade fiscal dos municípios.

iii. Nível Econômico do Município: representado pelo Produto Interno Bruto (PIB) a preços correntes, expressos em milhares de reais, no município em um ano. Os dados relativos ao PIB foram coletados na homepage do Instituto Brasileiro de Geografia e Estatística (IBGE), que disponibiliza séries anuais para municípios a partir do ano de 1996. Embora tenham sido considerados grandes municípios brasileiros, os valores do PIB apresentam magnitudes diferentes, pelo que se optou por considerar o logaritmo natural do PIB dos municípios em cada ano. Styles e Tennyson (2007) utilizaram essa variável numa pesquisa de finalidade semelhante e encontraram relação positiva e significativa com desempenho fiscal em municípios norte-americanos. Além disso, de acordo com Akutsu e Pinho (2002) e Santana Jr. (2008), em geral espera-se que municípios com maior nível de atividade econômica apresentem melhores desempenhos em indicadores fiscais. Assim, propõe-se a hipótese de que o nível econômico é uma característica que tem influência significativa no nível de responsabilidade fiscal dos municípios.

iv. Autonomia Financeira: representada pelo percentual de participação das receitas próprias do município em relação à receita total arrecadada. As receitas próprias são aquelas obtidas pelo esforço fiscal da gestão municipal na busca de recursos para custeio dos serviços públicos, diferente das receitas obtidas mediante transferências, as quais são garantidas constitucionalmente aos municípios ou obtidas mediante a assinatura de convênios. Segundo Afonso e Araújo (2000), é comum a ideia de que as prefeituras dependem basicamente de transferências repassadas pelas esferas superiores. No entanto, os autores asseguram que, após a Constituição de 1988, houve um forte incremento da arrecadação própria municipal, decorrente dos investimentos realizados na máquina fazendária municipal. Akutsu e Pinho (2002) consideram que em geral se espera que municípios com maior autonomia financeira apresentem melhores desempenhos em indicadores fiscais. A partir disso, propõe-se a hipótese de que a autonomia financeira é uma característica que tem influência significativa no nível de responsabilidade fiscal dos municípios.

v. Nível de Endividamento: representada pela resultante da divisão da dívida total (que compreende as obrigações financeiras assumidas em operações de crédito, independente do prazo de amortização, apresentadas no balanço patrimonial ao final do exercício) pela receita total em cada ano. Essa variável representa o comprometimento do município com obrigações futuras e para fins deste estudo espera-se que municípios com maior nível de endividamento apresentem menores níveis de responsabilidade fiscal. Assim, admite-se a hipótese de que o nível de endividamento é uma característica que tem influência significativa no nível de responsabilidade fiscal dos municípios (Brender e Drazen, 2005).

vi. Ciclo Político: característica representada pela variável binária mandato, a qual se refere ao ciclo político de governo, sendo 0 para primeiro mandado e 1 para segundo mandato, ou seja, após reeleição do gestor municipal, instrumento introduzido no Brasil por meio da Emenda Constitucional no 16/1997. Os dados relativos ao mandato dos prefeitos foram obtidos na homepage do Tribunal Superior Eleitoral (TSE), que disponibiliza dados das eleições anteriores desde 
1994. Diversos estudos (Barro, 1973; Ferejohn, 1986; Mendes e Rocha, 2003; Brender e Drazen, 2005; Costa, 2006; Ferraz e Finan, 2011) têm apontado que a possibilidade de reeleição afeta as escolhas dos governantes no exercício de poder. Isso indica que, dada a possibilidade de reeleição, um gestor pode adotar medidas mais responsáveis do ponto de vista fiscal; assim, as escolhas em relação a gastos e medidas fiscais poderiam ter outra configuração na impossibilidade de continuar o mandato. A partir disso, admite-se a hipótese de que o ciclo político é uma característica que tem influência significativa no nível de responsabilidade fiscal dos municípios. Logo, espera-se que no primeiro mandato o resultado seja de maior responsabilidade fiscal e, portanto, indicadores mais equilibrados, por conta da expectativa de reeleição.

vii. Região: variável categórica que consiste no agrupamento dos municípios de acordo com a região geográfica onde se situa o estado a que pertencem. As categorias são: Norte (N), Nordeste (NE), Centro-Oeste (CO), Sudeste (SE) e Sul (S). Costa (2006) utilizou essa variável na análise da relação entre reeleição e política fiscal. No que tange a essa variável, espera-se que os municípios localizados em regiões mais desenvolvidas apresentem melhores desempenhos no indicador de responsabilidade fiscal. Dessa forma, propõe-se a hipótese de que a região é uma característica que tem influência significativa no nível de responsabilidade fiscal dos municípios.

viii. Localização: variável categórica, consiste no agrupamento dos municípios de acordo com a localização de cada um a partir dos seguintes elementos: capital, região metropolitana e interior do estado. A classificação dos municípios quanto à localização foi considerada de acordo com o proposto pelo Instituto Brasileiro de Geografia e Estatística (IBGE). Em um estudo da relação entre reeleição e política fiscal, Costa (2006) utilizou essa variável de controle. Em relação a essa variável, espera-se que os municípios que sejam capitais ou se localizem em regiões metropolitanas apresentem melhores desempenhos no indicador de responsabilidade fiscal. Assim, admite-se a hipótese de que a localização é uma característica que tem influência significativa no nível de responsabilidade fiscal dos municípios.

Tendo em vista objetivo de estimar um modelo de regressão que contribua para identificar características que expliquem o nível de responsabilidade fiscal dos municípios, e com base nas constatações de pesquisas empíricas acerca dos fatores potencialmente relacionados, foi testado o modelo apresentado a seguir:

Modelo: IRF em função das variáveis tamanho, nível econômico, autonomia financeira, endividamento, ciclo político, região e localização, com efeitos grupo e tempo.

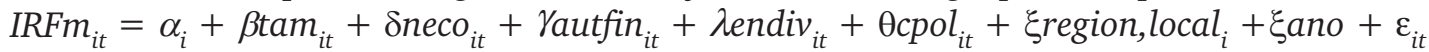
Em que:

$I R F m_{i t}=$ indicador do nível de responsabilidade fiscal do município i no ano $\mathrm{t}$ $\operatorname{tam}_{i t}=$ variável representativa de tamanho do município i no ano t, medido pela arrecadação total

$n e o_{i t}=$ variável representativa de nível econômico do município i no ano t, medido pelo PIB autfin $_{i t}=$ variável representativa de nível de autonomia financeira do município i no ano $\mathrm{t}$ endiv $_{i t}=$ variável representativa de nível de endividamento do município i no ano $\mathrm{t}$ $\mathrm{cpol}_{i t}=$ variável representativa de ciclo político, que evidencia gestores em primeiro ou segundo mandato, após reeleição region, local $_{i}=$ variável representativa de região e localização do município $a n o_{i t}=$ variável representativa do período t do município $\mathrm{i}$ 


\subsection{Limitações do estudo}

Admite-se que a presente pesquisa traz em seu bojo algumas limitações que devem ser consideradas quando da leitura da análise dos resultados e das conclusões. Uma das limitações consiste no procedimento amostral, em que se optou por investigar grandes municípios brasileiros, a cujos dados se tem maior acesso. Apesar dessa opção, quatro municípios foram excluídos por indisponibilidade de dados.

Considera-se ainda que a escolha das proxies por si só já impõe limitações ao estudo. Ressalta-se, porém, que são estas as informações disponíveis e que nesse estudo admite-se que essas informações não sofreram grandes mudanças ao longo do tempo, podendo ser consideradas características dos municípios.

\section{Apresentação dos resultados}

O presente estudo tem como objetivo identificar características que contribuem para explicar o nível da responsabilidade fiscal de grandes municípios brasileiros, medido por meio do subíndice fiscal do IRFS. A amostra da pesquisa é composta por 95 municípios, entre os mais populosos do Brasil. Para analisar a relação entre as variáveis estudadas, são empregadas as técnicas econométricas, com modelo de dados em painel, com a utilização do programa econométrico EViews 6.

A tabela 1 apresenta o quantitativo da classificação dos municípios estudados por região e localização.

Tabela 1

Região e localização dos municípios

\begin{tabular}{|lrrlll|}
\hline Região & F & FR & Localização & F & RF \\
\hline CO & 5 & 0,053 & Capital & 25 & 0,263 \\
NE & 21 & 0,221 & RM & 37 & 0,389 \\
N & 7 & 0,074 & Interior & 33 & 0,347 \\
SE & 46 & 0,484 & & & \\
S & 16 & 0,168 & & & \\
Total & 95 & 1 & Total & 95 & 1 \\
\hline
\end{tabular}

Fonte: Elaborada pelos autores.

Em relação à região geográfica dos municípios, verifica-se que 48,4\% dos municípios da amostra estão situados na região Sudeste, a região mais populosa e desenvolvida do país. Porém, todas as cinco regiões geográficas do Brasil estão contempladas na amostra. Quanto à localização dos municípios, observa-se que 25 (25\%) são capitais, pouco mais de um terço (34,7\%) é de municípios situados no interior dos estados e maior frequência foi verificada 
para municípios situados em regiões metropolitanas, sejam em torno ou não da capital do estado, 37, o que representa $38,9 \%$.

Tabela 2

Estatísticas descritivas da variável IRF

\begin{tabular}{|llccc|}
\hline IRF & Média & Mínimo & Máximo & Desvio-padrão \\
\hline 2002 & 0,4739 & 0,3345 & 0,6093 & 0,0471 \\
2003 & 0,4658 & 0,2912 & 0,5754 & 0,0354 \\
2004 & 0,4844 & 0,3442 & 0,6767 & 0,0452 \\
2005 & 0,5057 & 0,3713 & 0,6897 & 0,0466 \\
2006 & 0,4959 & 0,3667 & 0,7252 & 0,0518 \\
2007 & 0,4985 & 0,3479 & 0,7649 & 0,0555 \\
2008 & 0,5067 & 0,3978 & 0,6219 & 0,0442 \\
2009 & 0,5005 & 0,3625 & 0,7403 & 0,0536 \\
\hline
\end{tabular}

Fonte: Elaborada pelos autores.

Destaca-se na tabela 2 que o IRF, de maneira geral, apresentou tendência de crescimento em sua média no período analisado. O menor nível no índice de responsabilidade fiscal foi observado no ano de 2003 (0,2912) e o maior índice foi constatado no ano de 2007 (0,7649). Como esse indicador varia de 0 a 1 , observa-se que, na maior parte dos anos estudados, 0 valor médio ficou abaixo da metade do valor máximo possível e em nenhum dos municípios considerados foi observado o valor máximo possível.

Tabela 3

Estatísticas descritivas da variável tamanho (receita orçamentária)

\begin{tabular}{|lrrrc|}
\hline Receita orçamentária & \multicolumn{1}{c}{ Média } & Mínimo & Máximo & Desvio-padrão \\
\hline 2002 & 508,91 & 55,68 & $9.443,71$ & $1.164,77$ \\
2003 & 570,14 & 61,56 & $10.920,77$ & $1.326,74$ \\
2004 & 669,98 & 85,38 & $13.128,09$ & $1.562,93$ \\
2005 & 745,49 & 98,92 & $15.070,86$ & $1.732,99$ \\
2006 & 844,87 & 118,42 & $17.146,86$ & $1.962,89$ \\
2007 & 984,55 & 134,28 & $20.564,61$ & $2.317,29$ \\
2008 & $1.180,35$ & 195,12 & $23.876,85$ & $2.689,53$ \\
2009 & $1.238,52$ & 209,61 & $24.863,59$ & $2.807,98$ \\
\hline
\end{tabular}

Fonte: Elaborada pelos autores.

Nota: Receita orçamentária: montante total (expresso em milhões de reais) arrecadado pelo município no exercício, considerando receitas correntes e de capital (valores nominais). 
A receita orçamentária dos grandes municípios brasileiros considerados na amostra desse estudo apresentou uma média crescente no período estudado, mas apresenta uma distribuição bastante heterogênea, por incluir municípios díspares como São Paulo (SP) ( $\mathrm{R} \$ 24,86$ bilhões de reais em 2009) e Juazeiro do Norte (CE) ( $\mathrm{R} \$ 209,61$ bilhões de reais em 2009). Em 2009, último ano analisado, a média de arrecadação do conjunto de municípios superou R \$ 1,2 bilhão de reais. Em geral trata-se de municípios com dinamismo econômico e com maior potencial de geração de receitas do que municípios de menor porte.

Tabela 4

Estatísticas descritivas da variável nível econômico (PIB)

\begin{tabular}{|ccccc|}
\hline PIB & Média & Mínimo & Máximo & Desvio-padrão \\
\hline 2002 & 8.011 .876 & 589.144 & 187.953 .256 & 21.176 .542 \\
2003 & 8.924 .314 & 663.746 & 209.555 .133 & 23.362 .965 \\
2004 & 10.176 .038 & 750.643 & 225.170 .382 & 25.550 .710 \\
2005 & 11.395 .653 & 827.634 & 261.455 .917 & 29.137 .588 \\
2006 & 12.507 .796 & 1.024 .558 & 282.892 .455 & 31.546 .873 \\
2007 & 14.256 .336 & 1.164 .673 & 323.154 .666 & 35.819 .108 \\
2008 & 15.914 .013 & 1.413 .194 & 356.980 .045 & 39.715 .880 \\
2009 & 17.233 .098 & 1.595 .504 & 389.317 .167 & 43.329 .850 \\
\hline
\end{tabular}

Fonte: Elaborada pelos autores.

Nota: Produto Interno Bruto (PIB) a preços correntes, expressos em milhares de reais, no município em um ano (valores correntes).

O Produto Interno Bruto dos grandes municípios brasileiros considerados na amostra deste estudo apresentou uma média crescente no período estudado, porém apresenta uma distribuição heterogênea, por incluir municípios com perfis econômicos bastante diferentes como São Paulo (SP) (R\$ 389,3 bilhões de reais em 2009) e Juazeiro do Norte (CE) (R\$ 1,59 bilhão de reais em 2009). Em 2009, último ano analisado, a média do Produto Interno Bruto do conjunto de municípios foi de $\mathrm{R} \$ 17,2$ bilhões de reais.

Tabela 5

Estatísticas da variável ciclo político

\begin{tabular}{|ccccc|}
\hline & \multicolumn{2}{c}{ 10 Mandato } & \multicolumn{2}{c|}{ 2o Mandato } \\
\cline { 2 - 5 } Ano & F & FR & F & FR \\
\hline 2002 & 49 & $51,6 \%$ & 46 & $48,4 \%$ \\
2003 & 49 & $51,6 \%$ & 46 & $48,4 \%$ \\
2004 & 49 & $51,6 \%$ & 46 & $48,4 \%$ \\
\hline
\end{tabular}




\begin{tabular}{|ccccc|}
\hline & \multicolumn{2}{c}{ 1o Mandato } & \multicolumn{2}{c|}{ 20 Mandato } \\
\cline { 2 - 5 } Ano & F & FR & F & FR \\
\hline 2005 & 74 & $77,9 \%$ & 21 & $22,1 \%$ \\
2006 & 74 & $77,9 \%$ & 21 & $22,1 \%$ \\
2007 & 74 & $77,9 \%$ & 21 & $22,1 \%$ \\
2008 & 74 & $77,9 \%$ & 21 & $22,1 \%$ \\
2009 & 56 & $58,9 \%$ & 39 & $41,1 \%$ \\
\hline
\end{tabular}

Fonte: Elaborada pelos autores.

A variável ciclo político, que corresponde ao primeiro ou segundo mandato de um prefeito, após reeleição revela que, para os municípios e períodos considerados, as eleições municipais de 1998 reelegeram o maior número de prefeitos, os quais não puderam se recandidatar nas eleições seguintes. Os anos de 2002, 2003 e 2004 são os que tiveram os primeiros prefeitos reeleitos a partir da permissão dada pela Emenda Constitucional no 16/1997. Já o ciclo 2005-08 apresentou o maior quantitativo de gestores municipais em primeiro mandato.

Tabela 6

Estatísticas descritivas da variável autonomia financeira

\begin{tabular}{|ccccc|}
\hline Autonomia financeira & Média & Mínimo & Máximo & Desvio-padrão \\
\hline 2002 & 0,3366 & 0,0324 & 0,6403 & 0,1466 \\
2003 & 0,3397 & 0,0126 & 0,6764 & 0,1525 \\
2004 & 0,3348 & 0,0379 & 0,6588 & 0,1508 \\
2005 & 0,3286 & 0,0219 & 0,6310 & 0,1464 \\
2006 & 0,3258 & 0,0646 & 0,6254 & 0,1374 \\
2007 & 0,3352 & 0,0455 & 0,6479 & 0,1464 \\
2008 & 0,3182 & 0,0617 & 0,6105 & 0,1409 \\
2009 & 0,3263 & 0,0441 & 0,6074 & 0,1361 \\
\hline
\end{tabular}

Fonte: Elaborada pelos autores.

A autonomia financeira é uma variável relacionada à capacidade do município de gerar receitas, sem depender de transferências governamentais de esferas superiores. No período considerado, essa variável apresentou uma tendência de redução em sua média, o que denota maior dependência dos municípios de recursos transferidos. Para o período considerado, o menor nível de autonomia financeira foi observado no ano de 2003 (0,0126), o que significa que apenas $1,26 \%$ das receitas do município decorre da sua competência tributária e base econômica; também no ano de 2003 constatou-se o maior nível de autonomia financeira 
$(0,6764)$, que indica que mais de dois terços das receitas municipais derivam da sua competência tributária e base econômica.

Tabela 7

Estatísticas descritivas da variável endividamento

\begin{tabular}{|ccccc|}
\hline Endividamento & Média & Mínimo & Máximo & Desvio-padrão \\
\hline 2002 & 0,4595 & 0,0000 & 2,8266 & 0,4449 \\
2003 & 0,4779 & 0,0000 & 2,8316 & 0,4709 \\
2004 & 0,4480 & 0,0000 & 2,8360 & 0,4275 \\
2005 & 0,5959 & 0,0216 & 3,9114 & 0,6301 \\
2006 & 0,5700 & 0,0000 & 3,4760 & 0,6103 \\
2007 & 0,6158 & 0,0316 & 2,3959 & 0,5693 \\
2008 & 0,6195 & 0,0245 & 2,6604 & 0,5682 \\
2009 & 0,6780 & 0,0000 & 2,0879 & 0,5680 \\
\hline
\end{tabular}

Fonte: Elaborada pelos autores.

O nível de endividamento é uma variável relacionada ao comprometimento das receitas futuras do município para o pagamento de obrigações e encargos de dívidas. No período, o nível médio de endividamento dos municípios incluídos neste estudo apresentou uma tendência de crescimento, iniciando com 45,95\% em 2002 e terminando com 67,8\% em 2009. No período analisado, em cinco anos foram observados municípios sem dívidas contraídas sob a forma de operações de crédito e o nível máximo de endividamento foi constatado no ano de 2005, com 3,91.

A Tabela 8 apresenta os resultados do teste de correlação de Pearson.

Tabela 8

Teste de correlação

\begin{tabular}{|lccc|}
\hline \multicolumn{1}{|c}{ Variável } & Coef. & Sig. & \\
\hline IRF & 1,00000 & & \\
Tamanho & 0,10100 & 0,00540 & $*$ \\
Nível econômico & 0,07700 & 0,03454 & $* *$ \\
Autonomia financeira & 0,02461 & 0,49815 & \\
Endividamento & $-0,24000$ & 0,00000 & $*$ \\
\hline
\end{tabular}

Fonte: Elaborada pelos autores.

Nota * Significância de 0,01; ** Significância de 0,05; *** Signifi-

cância de 0,10 .

A partir da tabela 8, observa-se que a matriz de correlação de Pearson revelou correlação positiva significativa entre a variável dependente e as variáveis explanatórias, tamanho e 
nível econômico; a variável endividamento apresentou correlação negativa significativa, conforme o pressuposto assumido no estudo. A variável autonomia financeira apresentou correlação positiva, mas não significativa com a variável dependente. Com esse resultado, pode-se considerar, a princípio, que existe relação linear entre as variáveis tamanho, nível econômico e endividamento, porém no caso da última variável trata-se de uma correlação negativa. Em relação às hipóteses admitidas, não se deve rejeitar a existência de relação entre as variáveis citadas e o IRF. De acordo com o teste realizado, a variável mais fortemente associada com o IRF é endividamento, seguida de tamanho e nível econômico.

Porém, a análise de correlação revelou um problema de colinearidade entre as variáveis nível econômico e tamanho, visto que a correlação entre essas duas variáveis foi de 0,942 (pvalor $<0,001)$. Portanto, decidiu-se pela permanência de apenas uma dessas variáveis, sendo escolhida a variável nível econômico (PIB).

Os modelos de regressão do IRF como função das variáveis quantitativas nível econômico, autonomia financeira e endividamento e da variável qualitativa ciclo político, foram testados considerando o modelo de regressão Pooling (agrupada) e modelo de efeitos fixos. Os resultados do teste $F$ indicaram que ambos os modelos possuem capacidade de explicar o comportamento da variável dependente, porém o modelo de efeitos fixos apresentou um $\mathrm{R}^{2}$ ajustado superior à regressão Pooling. Como a regressão conforme o modelo de efeitos fixos foi significativa, para confirmar a existência dos efeitos grupo e tempo, procedeu-se o teste de Chow (teste $F$ ). Os resultados desse teste são apresentados na tabela 9.

Tabela 9

Teste de Chow

\begin{tabular}{|lccc|}
\hline Effects Test & Statistic & d.f. & Prob. \\
\hline Cross-section F & 6,951143 & $-94,654$ & 0.0000 \\
Period F & 7,077364 & $-7,654$ & 0.0000 \\
Cross-Section/Period F & 7,839364 & $-101,654$ & 0.0000 \\
\hline
\end{tabular}

Fonte: Elaborada pelos autores.

$\mathrm{O}$ primeiro teste $\mathrm{F}$ se relaciona com o efeito grupo (Cross-section $\mathrm{F}$ ). Com valor da estatística $\mathrm{F}$ de 6,9511 e um prob. próximo a zero, implica não aceitação da hipótese nula, logo, existe o efeito grupo. O segundo teste F se relaciona com o efeito tempo (Period F). Com valor da estatística F de 7,077 e um prob. próximo a zero, implica não aceitação da hipótese nula $(\alpha=0,05)$, logo, existe o efeito tempo. O terceiro teste $\mathrm{F}$ se relaciona com a existência do efeito grupo e efeito tempo. O valor da estatística $\mathrm{F}$ é de 7,8393, com prob. próximo a zero. Esses resultados indicam a existência dos efeitos conjuntos.

Os resultados da estimação com modelo de efeitos fixos são apresentados a seguir: 
Tabela 10

Resultados da regressão com modelo efeitos fixos

\begin{tabular}{|lccccc|}
\hline & & \multicolumn{5}{c|}{ Efeitos fixos } \\
\hline Variável & Coef. & S.E. & t-Statistic & Prob. \\
\hline nível econômico & -0.009208 & 0.017946 & -0.513074 & 0.6081 & \\
autonomia financeira & 0.039838 & 0.029979 & 1.328874 & 0.1844 & \\
endividamento & -0.015915 & 0.003675 & -4.330316 & 0.0000 \\
ciclo político & -0.003515 & 0.002997 & -1.172613 & 0.2414 & $*$ \\
C & 0.568281 & 0.156182 & 3.638593 & 0.0003
\end{tabular}$\quad *$

Fonte: Elaborada pelos autores.

Nota: * Significância de 0,01; ** Significância de 0,05; *** Significância de 0,10.

Verifica-se que a regressão com modelo de efeitos fixos, com um prob. próximo a zero no teste $\mathrm{F}$, possui capacidade de explicar o comportamento da variável dependente. No teste de significância (teste $\mathrm{t}$ ) das variáveis explanatórias, somente a variável representativa de endividamento apresentou significância. A capacidade explicativa da regressão por efeitos fixos ( $\mathrm{R}^{2}$ ajustado) é de $52,3 \%$.

O modelo de efeitos fixos admite que pode existir o efeito grupo e/ou o efeito tempo e que ambos são observáveis através de mudança, geralmente, no intercepto. O modelo de efeitos aleatórios, assim como o modelo de efeitos fixos, admite que pode existir o efeito grupo e/ ou o efeito tempo. Entretanto, ambos os efeitos não são observáveis, sendo representados por um termo aleatório (erro). Estimou-se a regressão com modelo de efeitos aleatórios considerando o efeito grupo (cross-section) e o efeito tempo (period). A estatística Rho do erro idiossincrático foi de 0,5603 , o que indica a existência de efeito tempo e efeito grupo. A seguir, são apresentadas as estatísticas da regressão com modelo de efeitos aleatórios, considerando os efeitos grupo e tempo.

Verifica-se que a regressão com modelo de efeitos aleatórios, com uma probabilidade próxima a zero no teste $\mathrm{F}$, possui capacidade de explicar o comportamento da variável dependente. No teste de significância (teste $t$ ) as variáveis explanatórias nível econômico e endividamento apresentaram significância. A capacidade explicativa da regressão ( $R^{2}$ ajustado) foi de $3,88 \%$. 
Tabela 11

Estatísticas da regressão com modelo de efeitos aleatórios

\begin{tabular}{|c|c|c|c|c|c|}
\hline \multirow[b]{2}{*}{ Variável } & \multicolumn{5}{|c|}{ Efeitos aleatórios } \\
\hline & Coef. & S.E. & $\mathrm{t}$-Statistic & Prob. & \\
\hline nível econômico & 0.006008 & 0.003467 & 1.733056 & 0.0835 & *** \\
\hline autonomia financeira & 0.019642 & 0.020609 & 0.953051 & 0.3409 & \\
\hline endividamento & -0.019123 & 0.003429 & -5.576601 & 0.0000 & $*$ \\
\hline ciclo político & -0.004503 & 0.002972 & -1.515009 & 0.1302 & \\
\hline C & 0.444983 & 0.028338 & 15.70279 & 0.0000 & $*$ \\
\hline R2 Ajustado & & & & 0.038839 & \\
\hline F-statistic & & & & 8.667579 & \\
\hline Prob(F-statistic) & & & & 0,000001 & \\
\hline \multicolumn{6}{|l|}{ Effects Specification } \\
\hline & & & S.D. & Rho & \\
\hline Cross-section random & & & 0.029458 & 0.4142 & \\
\hline Period random & & & 0.007310 & 0.0255 & \\
\hline Idiosyncratic random & & & 0.034259 & 0.5603 & \\
\hline
\end{tabular}

Fonte: Elaborada pelos autores.

Nota: * Significância de 0,01; ** Significância de 0,05; *** Significância de 0,10.

No modelo utilizado foi admitida a existência dos efeitos grupo e tempo, logo, o erro composto possui a seguinte configuração: $\eta_{i t}=u_{i}+\varepsilon_{i t}$. Os termos de erro associado com a regressão $\left(\varepsilon_{i t}\right)$ ou erro idiossincrático possuem uma correlação de 0,5603. Em função desse resultado, presume-se que existe o erro composto. Para confirmar a existência do erro composto procedeu-se ao teste de Breush-Pagan-Godfrey, apresentado a seguir.

\section{Tabela 12}

Teste para verificar a existência de erro composto

\begin{tabular}{|lcll|}
\hline \multicolumn{4}{|l|}{ Heteroskedasticity Test: Breusch-Pagan-Godfrey } \\
\hline F-statistic & 3.941946 & Prob. F(4,755) & 0.0036 \\
Obs*R-squared & 15.54750 & Prob. Chi-Square(4) & 0.0037 \\
Scaled explained SS & 40.40368 & Prob. Chi-Square(4) & 0.0000 \\
\hline
\end{tabular}

Fonte: Elaborada pelos autores.

Com um prob. de 0,0037, rejeita-se a hipótese nula do teste e conclui-se que o erro é heterocedástico, logo, existe o erro composto. A interpretação deste teste, para dados em painel, deve ser a seguinte: (i) se o erro é homocedástico, não é possível utilizar o modelo de efeitos aleatórios, logo o resultado do teste $\mathrm{F}$ (Chow) ajudará a identificar o melhor modelo a ser 
utilizado (regressão agrupada ou modelo de efeitos fixos); e (ii) se o erro é heterocedástico, existirá o erro composto, logo o resultado do teste de Hausman ajudará na identificação do melhor modelo (modelo de efeitos fixos ou modelo de efeitos aleatórios).

Como admitiu-se a existência de erro composto, a seguir apresenta-se o teste de especificação de Hausman, que tem como objetivo identificar se o estimador utilizado na regressão com um modelo de efeitos aleatórios (mínimos quadrados generalizados) é um estimador consistente, quando comparado com o estimador utilizado na regressão com um modelo de efeitos fixos (mínimos quadrados ordinários).

Tabela 13

Teste de especificação de Hausman

\begin{tabular}{|c|c|c|c|}
\hline \multicolumn{4}{|c|}{ Correlated Random Effects - Hausman Test } \\
\hline Test Summary & Chi-Sq. Statistic & Chi-Sq. d.f. & Prob. \\
\hline Cross-section and period random & 22.740441 & 4 & 0.0001 \\
\hline
\end{tabular}

Fonte: Elaborada pelos autores.

O teste realizado se relaciona com os efeitos grupo e tempo, de acordo com suposição anteriormente apresentada. Com valor da estatística qui-quadrado de 22,7404 e um prob. de 0,0001, implica não aceitação da hipótese nula, logo, o efeito é fixo.

Assim, pode-se considerar que existem diferenças significativas entre os municípios (cross-section) e entre os anos (period), o que sugere uma aproximação com o modelo de regressão pooling. A partir dessa constatação, estimou-se uma regressão Pooling com dummies para região, localização e tempo. A atribuição de variáveis dummies para cada região e localização permite controlar as diferenças entre as unidades (cross section). Já a inclusão de variáveis dummies para cada ano permite controlar as diferenças dos diversos períodos analisados.

Os resultados da regressão Pooling incluindo as variáveis dummies de região, localização e tempo, são apresentados na tabela 14 .

\section{Tabela 14}

\section{Resultados da regressão Pooling com variáveis dummy de região e localização}

\begin{tabular}{|lccccc|}
\hline Variável & Coef. & S.E. & t-Statistic & Prob. & \\
\hline nível econômico & 0.009452 & 0.002640 & 3.580213 & 0.0004 & $*$ \\
autonomia financeira & 0.037278 & 0.015249 & 2.444605 & 0.0147 & $* *$ \\
endividamento & -0.032013 & 0.003808 & -8.406654 & 0.0000 & $*$ \\
ciclo político & -0.001439 & 0.003474 & -0.414073 & 0.6789 & \\
região metropolitana & 0.014029 & 0.005896 & 2.379364 & 0.0176 & $*$ \\
interior & 0.030633 & 0.006557 & 4.671652 & 0.0000 & $*$ \\
\hline
\end{tabular}




\begin{tabular}{|lcccccc|}
\hline Variável & Coef. & S.E. & t-Statistic & Prob. & \\
\hline Centro-Oeste & -0.004238 & 0.007456 & -0.568404 & 0.5699 & \\
Nordeste & -0.000911 & 0.006123 & -0.148830 & 0.8817 & \\
Sudeste & -0.006505 & 0.004820 & -1.349717 & 0.1775 & \\
Norte & 0.015188 & 0.008424 & 1.802841 & 0.0718 & $* * *$ \\
D2002 & -0.026151 & 0.007029 & -3.720293 & 0.0002 & $*$ \\
D2003 & -0.034913 & 0.006512 & -5.360908 & 0.0000 & $*$ \\
D2004 & -0.018428 & 0.006862 & -2.685514 & 0.0074 & $*$ \\
D2005 & 0.006480 & 0.006811 & 0.951344 & 0.3417 & \\
D2006 & -0.005139 & 0.007301 & -0.703944 & 0.4817 & \\
D2007 & -0.002630 & 0.007674 & -0.342771 & 0.7319 & \\
D2008 & 0.005292 & 0.007037 & 0.751961 & 0.4523 & \\
C & 0.411180 & 0.025679 & 16.01223 & 0.0000 & $*$ \\
\hline Adjusted R-squared & & & & 0.204646 & \\
F-statistic & & & & & 12.48779 & \\
Prob (F-statistic) & & & & & & \\
\hline
\end{tabular}

Fonte: Elaborada pelos autores.

Nota: * Significância de 0,01; ** Significância de 0,05; *** Significância de 0,10.

Verifica-se que a regressão, com uma probabilidade próxima a zero no teste $\mathrm{F}$, possui capacidade de explicar o comportamento da variável dependente. A capacidade explicativa da regressão ( $\mathrm{R}^{2}$ ajustado) foi de $20,46 \%$. No teste de significância (teste $t$ ) das variáveis explanatórias, as variáveis nível econômico e endividamento apresentaram significância a 1\% e a variável autonomia financeira apresentou significância a 5\%. A variável ciclo político não apresentou significância e seu coeficiente é considerado estatisticamente igual a zero.

Além disso, as variáveis dummy representativas de localização, região metropolitana e interior são significantes a 5\% e 1\%, respectivamente, sendo ambas com sinal positivo. Por sua vez, apenas a variável de região Norte é significante com sinal positivo. Além disso, as variáveis dos anos 2002, 2003 e 2004 apresentaram-se significativas com sinal negativo.

Com isso pode-se considerar que as características que contribuem de forma significativa para explicar o nível de responsabilidade fiscal dos municípios incluídos na amostra desse estudo são: nível econômico, endividamento e autonomia financeira. A variável representativa de ciclo político apresentou relação não significativa com o indicador de responsabilidade fiscal.

Os resultados obtidos para a variável região dão destaque aos desempenhos da região Norte. Uma possível justificativa para o bom desempenho da região Norte está associado ao 
baixo número de observações (apenas sete), podendo estes municípios serem os melhores representantes em relação à responsabilidade fiscal e não retratarem a realidade da região.

Em relação à variável localização, o resultado foi inverso ao esperado, visto que o grupo das capitais teve o pior desempenho. Isto se deve ao fato de que esse grupo apresenta maior heterogeneidade, com a presença de grandes cidades como São Paulo e Rio de Janeiro e também de cidades de menor porte como Porto Velho, Cuiabá e Aracaju. Enquanto isso, o grupo do interior é representado de forma mais homogênea por cidades de atividade econômica mais intensa e maior atratividade populacional, fazendo-as compor a amostra.

No que tange às variáveis representativas de ano, verificou-se que os anos de 2002, 2003 e 2004 estão associados a piores desempenhos no índice de responsabilidade fiscal. Uma possível explicação para esse resultado é que tais anos constituem os anos de adaptação dos limites e indicadores de responsabilidade na gestão fiscal determinados pela LRF, conforme constatação de Giuberti (2005).

Em relação aos pressupostos da análise de regressão, tem-se que: a autocorrelação serial dos resíduos não foi detectada na estatística de Durbin-Watson, que apresentou valor próximo a 2,00 (1,9844), e nem no teste LM Breusch-Godfrey, que apresentou p-valor de 0,3080 (maior que a significância de 0,05). Além disso, não se observaram problemas de multicolinearidade perfeita entre as variáveis explanatórias. Porém, se observaram problemas de heterocedasticidade, já que tanto o teste de White, quanto o teste de BreuschPagan-Godfrey, apresentaram p-value inferior ao nível de 5\% ( $p$-value $=0,0015)$. Porém, os resultados apresentados já estão robustos à heterocedasticidade, por conta da aplicação da correção de White aos erros-padrão. Por fim, observa-se que a regressão apresentou problemas com o pressuposto de normalidade dos resíduos, visto que o teste de JarqueBera apresentou p-value de 0,000. Porém, de acordo com Brooks (2008), considerando-se o teorema do limite central e que a amostra contou com 760 observações, este pressuposto pode ser relaxado.

\section{Conclusões}

O objetivo desse estudo foi identificar os possíveis determinantes da responsabilidade fiscal de grandes municípios brasileiros. O estudo foi conduzido com foco em municípios de grande porte, a partir de uma amostra final de 95 municípios, que contemplam todas as cinco regiões geográficas brasileiras, e estão divididos em capital, municípios do interior e municípios localizados em regiões metropolitanas, com abrangência no período de 2002 a 2009. As variáveis consideradas no estudo foram: nível de responsabilidade fiscal, tamanho, nível econômico, autonomia financeira, nível de endividamento, ciclo político, região, localização dos municípios e ano.

Os resultados encontrados permitem concluir que: o nível de responsabilidade fiscal dos municípios da amostra foi considerado incipiente e em média ficou abaixo de 50\% do nível 
máximo possível. Constatou-se ainda que o nível de responsabilidade fiscal está positivamente relacionado com nível econômico e autonomia financeira e negativamente relacionado com o nível de endividamento dos municípios.

O modelo de regressão estimado indica que as variáveis nível econômico, endividamento e autonomia financeira podem contribuir para explicar as variações no nível de responsabilidade fiscal dos municípios. Além dessas, variáveis dummy representativas de região e localização apresentaram significância e podem ser associadas à variação no nível de responsabilidade fiscal. O modelo final consegue explicar em torno de $20,46 \%$ das variações no nível de responsabilidade fiscal dos municípios, medido pelo IRFS da Confederação Nacional dos Municípios. Com esses resultados, admitiu-se que existem diferenças significativas entre os municípios e entre os anos.

Em relação aos pressupostos inicialmente assumidos, tem-se que: em geral, os municípios brasileiros pesquisados apresentam um nível incipiente de responsabilidade fiscal, uma vez que esse nível foi medido com base no cumprimento de dispositivos legais e se trata de municípios de grande porte; as variáveis representativas de nível econômico e autonomia financeira apresentaram relação positiva significativa com o nível de responsabilidade fiscal, conforme esperado; por sua vez, a variável endividamento apresentou relação negativa com o IRF, também como se esperava; a variável ciclo político não apresentou relação significativa com a variável dependente.

Adicionalmente, o modelo de regressão estimado revelou que variáveis de região e localização podem contribuir para explicar as variações no nível de responsabilidade fiscal dos municípios e que as variáveis de ano corroboram que os primeiros anos posteriores à aprovação da LRF foram períodos de adaptação às regras impostas, uma vez que muitos municípios se encontravam com as finanças desequilibradas no período, conforme apontado em estudos empíricos.

Para pesquisas futuras, sugere-se adotar outras proxies que contribuam para explicar as variações no nível de responsabilidade fiscal dos municípios, com vistas a contribuir na definição de métricas de avaliação da responsabilidade e eficiência fiscal, além dos dispositivos constantes dos instrumentos normativos.

\section{Referências}

ABRUCIO, Fernando L. Desafios contemporâneos para a reforma da administração pública brasileira. In: PETERS, B. Guy; PIERRE, Jon. Administração pública: coletânea. São Paulo: Unesp, 2010. cap. 24.

AFONSO, José Roberto R.; ARAÚJO, Erika A. A capacidade de gasto dos municípios brasileiros: arrecadação própria e receita disponível. Cadernos de Finanças Públicas Esaf, Brasília, n. 1, p. 1930, 2000. 
AKUTSU, Luiz; PINHO, José A. G. Sociedade da informação, accountability e democracia delegada: investigação em portais de governo no Brasil. Rev. Adm. Pública, Rio de Janeiro, v. 36, n. 5, p. 723745, set./out. 2002.

BARRETO, Flavio A. F. D.; MENDONÇA, Heloisa H. M. Autonomia financeira, responsabilidade fiscal e seus efeitos sobre os indicadores sociais dos estados brasileiros. Cadernos de Finanças Públicas Esaf, Brasília, n. 10, p. 59-85, dez. 2010.

BARRO, Robert J. The control of politicians: an economic model. Public Choice, v. 14, n. 1, p. 1942, 1973.

BITTENCOURT, Jeferson L. Evidências de ciclo político na economia brasileira: um teste para a execução orçamentária dos governos estaduais - 1983/2000. Dissertação (mestrado em economia) — Universidade Federal do Rio Grande do Sul, Porto Alegre, 2002.

BLAIS, Andre; NADEAU, Richard. The electoral budget cycle. Public Choice, v. 74, n. 4, p. 389-403, Springer 1992.

BRASIL. Constituição da República Federativa do Brasil, 1988. Disponível em: <www.planalto.gov. br/ccivil_03/constituicao/constitui\%C3\%A7ao.htm>. Acesso em: 14 jul. 2012.

BRASIL. Lei Complementar Federal no 101 de 4 de maio de 2000. Estabelece normas de finanças públicas voltadas para a responsabilidade fiscal e dá outras providências. Disponível em: <www. planalto.gov.br/ccivil_03/leis/lcp/lcp101.htm>. Acesso em: 14 jul. 2012.

BRENDER, Adi; DRAZEN, Allan. How do budget déficits and economic growth affect reelection prospects? Evidence from a large cross-section of coutries. National Bureau of Economic Research, Working Paper 11862, 2005.

BROOKS, Chris. Introductory econometrics for finance. $2^{\text {nd }}$ edition. Cambridge, UK: Cambridge University Press, 2008.

COSTA, Mylena M. A. Reeleição e política fiscal: um estudo dos efeitos da reeleição nos gastos públicos. 2006. Dissertação (mestrado em economia do setor público) — Departamento de Economia, Universidade de Brasília, Brasília, 2006.

FEREJOHN, John. Incumbent performance and electoral control. Public Choice, v. 50, n. 1-3, p. 5-25, 1986.

FERRAZ, Claudio; FINAN, Frederico. Electoral accountability and corruption: evidence from the audits of local governments. American Economic Review, v. 101, n. 4, p. 1274-1311, 2011.

GIUBERTI, Ana C. Efeitos da lei de responsabilidade fiscal sobre os gastos dos municípios brasileiros. Dissertação (mestrado em economia) — Universidade de São Paulo, São Paulo, 2005.

GOBETTI, Sérgio W.; KLERING, Luis R. Índice de Responsabilidade Fiscal e qualidade de gestão: uma análise combinada baseada em indicadores de estados e municípios. Brasília: Esaf, 2007. Disponível em: <www.tesouro.fazenda.gov.br/premio_TN/XIIPremio/conteudo_catalogos_pr12.html>. Acesso em: 14 jul. 2012. 
HEALD, David. Fiscal transparency: concepts, measurement and UK practice. Public Administration, v. 81, n. 4, p. 723-759, 2003.

INSTITUTO BRASILEIRO DE GEOGRAFIA E ESTATÍSTICA. Censo 2010. Disponível em: <www. ibge.gov.br >. Acesso em: 14 jul. 2012.

MENDES, Marcos. Federalismo fiscal e crescimento do governo: evidências eleitorais para o Brasil. In: ENCONTRO NACIONAL DE ECONOMIA (ANPEC), XXXII, 2004, João Pessoa. In: Anais... João Pessoa: Anpec, 2004. p. 1-16.

MENDES, Marcos; ROCHA, Carlos A. A. Reeleição sob informação imperfeita: evidências para os municípios brasileiros. Brasília: Departamento de Economia, Universidade de Brasília, 2003. (Série Textos para Discussão, n. 313)

MENEGUIN, Fernando B.; BUGARIN, Maurício S. Reeleição e política fiscal: um estudo dos efeitos da reeleição nos gastos públicos? Revista de Economia Aplicada, v. 5, n. 3, p. 601-622, 2001.

MENEGUIN, Fernando B.; BUGARIN, Maurício S.; CARVALHO, Alexandre X. de. O que leva um governante à reeleição? Brasília: Ipea, 2005. (Texto para Discussão n. 1135)

NAKAGUMA, Marcos Y.; BENDER, Siegfried. A emenda da reeleição e a Lei de Responsabilidade Fiscal: impactos sobre ciclos políticos e performance fiscal dos Estados (1986-2002). Econ. Apl. [online], v. 10, n. 3, p. 377-397, 2006.

NASCIMENTO, Edson R. Gestão pública. 2. ed. São Paulo: Saraiva, 2010.

NASCIMENTO, Leonardo S.; VICENTE, Ernesto F. R. A efetividade dos ciclos políticos nos municípios brasileiros: um enfoque contábil. Revista de Contabilidade e Organizações, São Paulo, v. 6, n. 14, p. 106-126, 2012.

PINHO, José A. G. Accountability em portais estaduais e municipais no Brasil: realidades distantes das promessas. In: ENCONTRO DE ADMINISTRAÇÃO PÚBLICA E GOVERNANÇA, II, 2006, São Paulo. Anais... São Paulo: Anpad, 2006. p. 1-17.

PORTO Natalia; PORTO Alberto. Fiscal decentralization and voter's choices as control. Journal of Applied Economics, v. 3, n. 1, p. 135-167, 2000.

ROMERO, David W. What they do does matter? Incumbent resource allocations and the individual house vote. Political Behavior, v. 28, n. 3, p. 241-258, 2006.

SANTANA JR., Jorge J. B. Transparência fiscal eletrônica: uma análise dos níveis de transparência apresentados nos sites dos poderes e órgãos dos Estados e do Distrito Federal do Brasil. Dissertação (mestrado em ciências contábeis) — Programa Multinstitucional e Inter-regional de Pós-graduação em Ciências Contábeis, Recife, 2008.

STYLES, Alan K.; TENNYSON, Mack. The accessibility of financial reporting of U.S. municipalities on the internet. Journal of Public Budgeting, Accounting \& Financial Management, v. 19, n. 1, p. 56-92, 2007. 
VIEIRA, Marcelo M. F.; ZOUAIN, Deborah M. Pesquisa qualitativa em administração. Rio de Janeiro: FGV, 2003. v. 1, cap. 1.

Claudia Ferreira da Cruz é professora assistente da Faculdade de Administração e Ciências Contábeis da Universidade Federal do Rio de Janeiro (Facc/UFRJ). E-mail: claudiacruz@facc.ufrj.br.

Marcelo Álvaro da Silva Macedo é professor adjunto do Programa de Pós-graduação em Ciências Contábeis da Faculdade de Administração e Ciências Contábeis da Universidade Federal do Rio de Janeiro (PPGCC-Facc/UFRJ).E-mail: malvaro@facc.ufrj.br.

Fernanda Filgueiras Sauerbronn é professora adjunta do Programa de Pós-graduação em Ciências Contábeis da Faculdade de Administração e Ciências Contábeis da Universidade Federal do Rio de Janeiro (PPGCC-Facc/UFRJ). E-mail: fernanda.sauerbronn@facc.ufrj.br. 
